Н. Н. Дармаева, Н. Б. Бадмаев, А. Ц. Мангатаев. Особенности агрегатного состава и водопрочности черноземов юга Витимского плоскогорья

Научная статья

УДК 631.4

DOI 10.18101/2587-7143-2021-2-31-39

\title{
ОСОБЕННОСТИ АГРЕГАТНОГО СОСТАВА И ВОДОПРОЧНОСТИ ЧЕРНОЗЕМОВ ЮГА ВИТИМСКОГО ПЛОСКОГОРЬЯ
}

\section{(C) Дармаева Нина Николаевна}

кандидат биологических наук, ведущий инженер лаборатории географии и экологии почв,

Институт общей и экспериментальной биологии СО РАН

Россия, 670047, г. Улан-Удэ, ул. Сахьяновой, 6

darmaeva.nina@gmail.com

\section{(C) Бадмаев Нимажап Баяржапович}

доктор биологических наук, профессор

кафедры земельного кадастра и землепользования ${ }^{1}$, заместитель директора по научной работе,

заведующий лабораторией географии и экологии почв ${ }^{2}$

${ }^{1}$ Бурятский государственный университет имени Доржи Банзарова

${ }^{2}$ Институт общей и экспериментальной биологии СО РАН

Россия, 670000, г. Улан-Удэ, ул. Смолина 24a

nima_b@mail.ru

\section{(C) Мангатаев Александр Цыренович}

кандидат биологических наук, ведущий инженер

лаборатории географии и экологии почв,

Институт общей и экспериментальной биологии СО РАН, Россия, 670047, г. Улан-Удэ, ул. Сахьяновой, 6

aleksandr_man@mail.ru

Аннотация. Проведен сравнительный анализ структурно-агрегатного состава мерзлотных черноземов юга Витимского плоскогорья, черноземов Русской равнины (Липецкая область) и Южного Урала (Челябинская область). Выявлены различия в структурном состоянии данных почв, которые заключается в отсутствии водопрочной структуры мерзлотных черноземов, несмотря на их хорошую оструктуренность при сухом просеивании. Поэтому изучение мезо- и микроморфологии почв юга Витимского плоскогорья должно быть продолжено в целях уточнения их классификационного положения.

Ключевые слова: водопрочность агрегатов, классификация почв, мокрое просеивание, склоновый рельеф, структурно-агрегатный состав, сухое просеивание, чернозем глинисто-иллювиальный мерзлотный, чернозем типичный, чернозем выщелоченный

\section{Благодарности}

Работа выполнена при финансовой поддержке гранта РФФИ № 19-29-05250 мк и проекта НИР № 121030100228-4.

\section{Для цитирования}

Дармаева Н. Н., Бадмаев Н. Б., Мангатаев А. Ц. Особенности агрегатного состава и водопрочности черноземов юга Витимского плоскогорья // Вестник Бурятского государственного университета. Биология. География. 2021. № 2. С. 31-39. 


\section{Введение}

Изучение почвенной структуры и в особенности ее агрегатного состава имеет более чем вековую историю. Впервые о почвенной структуре как обособленном свойстве почвенного профиля упоминается в работах И. М. Комова, где подробно описываются практически все физические свойства почв, связанные со структурой. Тема получила свое развитие в трудах В. В. Докучаева, А. Таера, М. Г. Павлова, Я. А. Линовского.

Большой вклад в изучение роли структуры в функционировании почв внесли И. Н. Антипов-Каратаев, Е. И. Кочерина, А. И. Личманова, В.В.Медведев, Н. А. Качинский, Е. В. Шеин, М. Ю. Милановский и др.

Отдельно следует указать целый пласт исследований, посвященных роли органического вещества в формировании почвенной структуры. В изучение этой проблематики большой вклад внесли Д. В. Хан, И. В. Кузнецова, Л. С. Травникова, Н. А. Титова, М. Ш. Шаймухаметов, Б. М. Когут, З. С. Артемьева.

В зарубежной литературе основные вехи изучения почвенной структуры связаны с работами R. Lang, G. Wiegner, L. Baver, E. Myers, A. Low, K. Barley, I. Hagin, G. Bodman [2].

В совокупности теории структурообразования Костычева, Вильямса и Гедройца хорошо объясняют особенности структуры. В частности, наиболее выраженная комковато-зернистая структура черноземов обусловлена их обогащенностью органическими и минеральными коллоидами с преобладанием гуминовых и ульминовых кислот, а также комплексных соединений с кальцием. Это обусловлено травянистой растительностью, обладающей мощной, разветвленной корневой системой; деятельностью дождевых червей и насекомых; периодическим просушиванием и промораживанием почвенной толщи и другими процессами. При движении от черноземной зоны на юго-восток и север отмечается ухудшение структуры почвы [8].

Изученные почвы по классификации почв России 2004 года определены как черноземы глинисто-иллювиальные квазилеевые мерзлотные. Действительно, при диагностике данных почв по морфологическому строению видно сходство на типовом уровне, это наличие темно-гумусового горизонта и нижележащего аккумулятивнокарбонатного горизонта ВСА, смещенного вниз относительно нижней границы темногумусового горизонта. Но здесь проявляются локальные фациальные особенности (наличие мерзлоты) и поэтому черноземы изученной территории отличаются от аналогичных европейской части России. В частности, укороченный почвенный профиль, резкоубывающее вниз по профилю содержание гумуса, гидротермический режим и, как следствие, отсутствие водопрочной структуры гумусовых горизонтов, которая является одной из важных характеристик черноземов.

Эти вопросы не были отражены в ранее выполненных работах, поэтому целью данного исследования являлось сравнение агрегатного состава и водопрочности агрегатов черноземов Еравнинской котловины, сформированных в склоновом рельефе, с черноземами типичными Русской равнины (Липецкая область) и черноземами выщелоченными Южного Урала (Челябинская область) для уточнения классификационного положения изученных нами почв.

\section{Объекты и методы}

Исследования проводились в пределах полигон-трансекта в Еравнинской лесостепной котловине Витимского плоскогорья (Республика Бурятия) на южном 
Н. Н. Дармаева, Н. Б. Бадмаев, А. Ц. Мангатаев. Особенности агрегатного состава и водопрочности черноземов юга Витимского плоскогорья

склоне увала крутизной до $8^{\circ}$. На вершине склона (элювиальная позиция - ЭП) и середине склона (транзитная позиция - ЭП) сформированы черноземы глинисто-иллювиальные квазиглеевые мерзлотные под твердовато-осоковыми и полевицевыми растительными сообществами. Общим для морфологии почв южного склона является автоморфный характер почвообразования в верхних горизонтах, в нижних появляются признаки гидроморфизма. О криогенезе свидетельствуют морозобойные трещины с глубокими гумусовыми затеками. Многолетнемерзлая толща, являясь барьером при вертикальной миграции влаги, обусловливает ее застой и периодически возникающий анаэробиоз. Значительная крутизна склона способствует формированию на поверхности почвы зоны смыва почвенной массы в направлении от вершины к подножию. Почвы отличаются высокой хрящеватостью.

Рассмотрены показатели гумусовых горизонтов почвы. Гранулометрический состав почв определяли пипет-методом с обработкой пирофосфатом натрия, агрегатный состав и водопрочность агрегатов, по Саввинову ${ }^{1}$. Расчетным методом определялись коэффициент структурности и критерий водопрочности агрегатов.

Проведен сравнительный анализ структурного состояния почв с черноземами типичными Липецкой области [10] и с черноземами выщелоченными Южного Урала [15].

\section{Результаты и обсуждение}

Мерзлотные почвы южного склона увала Еравнинской котловины характеризуются суглинистым гранулометрическим составом. Частицы физической глины активно перемещаются по склону и аккумулируются в подножии в аллювиальной луговой почве. Содержание гумуса в темногумусовом горизонте чернозема на вершине склона высокое, в почве транзитной зоны - низкое. Распределение гумуса резко убывающее вниз по профилю [7].

Во всех рассматриваемых почвах структура комковато-зернистая (ореховатозернистая). На диаграмме приведены данные сухого и мокрого просеивания.

Как видно, при сухом просеивании чернозема мерзлотного на вершине склона (ЭП) присутствуют все типы структурных агрегатов. Преобладающими являются агрегаты размером 1-5 мм, меньше всего содержание агрегатов $<0,25$ мм. При мокром просеивании практически полностью разрушаются агрегаты больше 1 мм. При этом доминирующей является фракция микроагрегатов $<0,25$ мм. Отмечается превышение количества агрегатов размером 0,25-1 мм в два раза по сравнению с результатами сухого просеивания.

В мерзлотном черноземе транзитной позиции (ТП) при сухом просеивании представлены агрегаты всех размеров. По сравнению с агрегатным составом почвы верхней позиции, здесь заметно возрастает количество микроагрегатов $<0,25$ и фракции 0,25-1 мм. Мало изменяется содержание агрегатов размером больше 5 мм. Преобладающей является фракция 1-5 мм. В отличие от почвы на вершине склона соотношение содержания сухих агрегатов изменяется вследствие существенного превышения агрегатов $<0,25$ мм. При мокром просеивании в гумусовом слое этой почвы активно разрушаются агрегаты $>1$ мм, обогащая фракции агрегатов 1-0,25 мм, но преобладает фракция $<0,25$ мм. Содержание в

${ }^{1}$ Теории и методы физики почв / под редакцией Е. В. Шеина и Л. О. Карпачевского. Москва: Гриф и К, 2007. 616 с. 
ней микроагрегатов в 7,5 раз превышает данные сухого просеивания и составляют $75 \%$ общей суммы агрегатов.

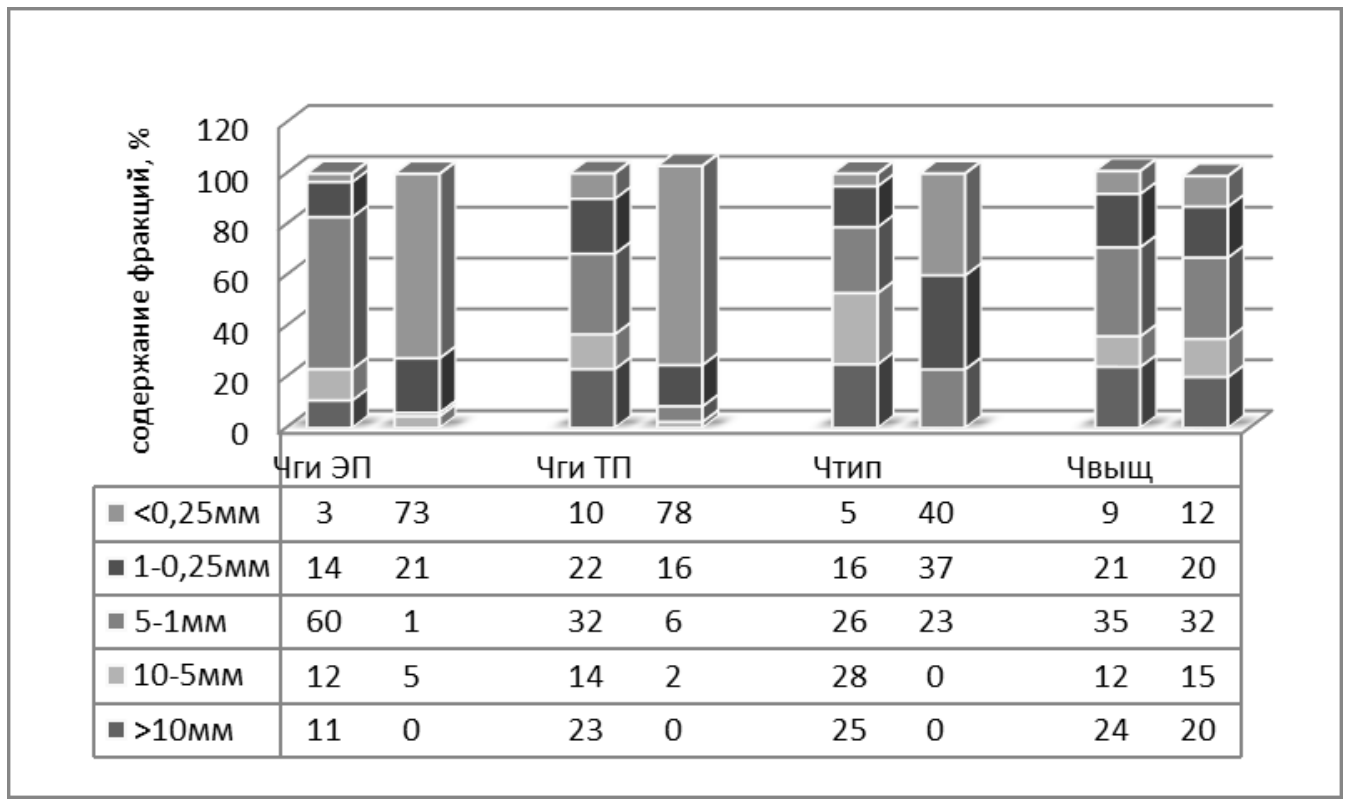

Рис. 1. Структурно-агрегатный состав почв (сухое/мокрое просеивание)

Примечание: Чги ЭП - чернозем глинисто-иллювиальный элювиальной позиции;

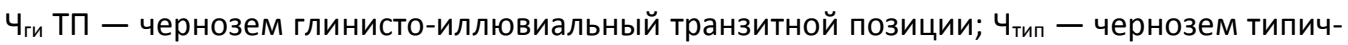
ный Русской равнины; Чвыщ - чернозем выщелоченный Южного Урала.

В обеих почвах резко возрастает содержание микроагрегатов. Но если при мокром просеивании в почве на вершине склона повышалось содержание не только микроагрегатов, но и фракции 1-0,25 мм по сравнению с сухим просеиванием, то в почве транзитной фации в той или иной степени разрушались агрегаты всех размерностей, а их фрагменты увеличивали количество агрегатов фракции $<0,25$ мм.

Таким образом, общим признаком агрегатного состава мерзлотных черноземов, формирующихся на разных позициях склона южной экспозиции, является отсутствие водопрочности агрегатов $>1$ мм, а в транзитной зоне и агрегатов $1-0,25$ мм. За счет дробления и диспергирования под воздействием воды агрегатов резко увеличивается «микроагрегированность» почв.

В образовании устойчивых агрегатов важную роль играют гуминовые кислоты, обогащенные кальцием. Кроме этого, водопрочные агрегаты формируются при содержании коллоидов в илистых частицах до $80 \%$. Цементирующими частицами являются $\mathrm{Ca}, \mathrm{Al}, \mathrm{Fe}[19]$.

Гуминовые кислоты мерзлотных почв отличаются слабой степенью зрелости и низкой устойчивостью, обусловленной значительным содержанием в их составе алифатических групп [4]. При невысоком содержании обменного кальция в почвах при мокром просеивании разрушаются агрегаты крупнее 1 мм и возрастает содержание фракции $<0,25$ мм. 
Н. Н. Дармаева, Н. Б. Бадмаев, А. Ц. Мангатаев. Особенности агрегатного состава и водопрочности черноземов юга Витимского плоскогорья

В черноземах типичных Русской равнины представлены агрегаты всех размерностей, их содержание постепенно снижается с уменьшением размера фракции, минимально содержание микроагрегатов. После мокрого просеивания в черноземе типичном разрушаются агрегаты больше 5 мм, пополняя фракции меньше 1 мм. Содержание наиболее ценной в агрономическом отношении фракции 1-5 мм остается практически неизменной, в отличие от мерзлотных черноземов, где агрегаты этой фракции разрушаются в значительной степени. Возможно, это связано с более плотной упаковкой элементарных почвенных частиц данной фракции и небольшой внутриагрегатной пористостью, которые препятствуют попаданию воды и, следовательно, разрушению агрегатов.

При изучении прочности почвенных агрегатов А.Д. Ворониным [5] было установлено, что она снижается с увеличением их размеров, обусловлено это повышением пористости агрегатов и уменьшением площади контактов в агрегате.

В более крупных агрегатах встречаются отдельные крупные пустоты, микротрещины. И под воздействием воды такие агрегаты быстро разрушаются, так как влага оказывает расклинивающее влияние. Агрегаты крупнее 5 мм распадаются на фрагменты всех размеров, в количествах, равных среднему образцу почвы.

Совершенно другой вид имеет распределение агрегатов в черноземе выщелоченном Южного Урала. В целом здесь при сухом и мокром просеивании сохраняются агрегаты всех размерностей, причем в количественном соотношении различия небольшие, что свидетельствует об их способности сохранять удовлетворительную макроструктуру, когда агрегаты почвы под воздействием воды разрушаются незначительно [15].

В таблице 1 показаны содержание агрономически ценных агрегатов, коэффициент структурности, критерий водопрочности АФИ и сумма агрегатов размерами $>0.25$ после мокрого просеивания для оценки структуры в отношении ее водоустойчивости.

Таблица 1

Параметры оценки структурного состояния и водоустойчивости черноземных почв

\begin{tabular}{|l|c|c|c|c|c|c|c|}
\hline \multicolumn{1}{|c|}{$\begin{array}{c}\text { Почва } \\
\text { Глубина, см }\end{array}$} & $\begin{array}{c}\text { Гумус, } \\
\%\end{array}$ & $\begin{array}{c}\text { Ил, } \\
\%\end{array}$ & $\begin{array}{c}\text { ФГ, } \\
\%\end{array}$ & Кстр & $\begin{array}{c}\text { Содержание } \\
\text { агрономически } \\
\text { ценных } \\
\text { агрегатов, } \%\end{array}$ & К АФИ & $\begin{array}{c}\text { Содержание } \\
\text { фракции >0,25 } \\
\text { мм при мокром } \\
\text { просеивании, } \%\end{array}$ \\
\hline Чги ЭП (0-24) & 6,22 & 24,2 & 31,8 & 6,1 & 86 & 155,1 & 27 \\
\hline Чги ТП (3-21) & 2,37 & 29,2 & 37,9 & 2 & 67 & 75 & 25 \\
\hline $\begin{array}{l}\text { Ч типичный (0-20) } \\
\text { Королев, 2006 }\end{array}$ & 6,8 & 30 & 58 & 2,4 & 86 & 377,8 & 71 \\
\hline $\begin{array}{l}\text { Ч выщелоченный } \\
\text { (0-20) } \\
\text { Сенькова, Гринец, } \\
2017\end{array}$ & 6,3 & 41,2 & 2,1 & 68 & 95 & 87 \\
\hline
\end{tabular}

Примечание: ФГ - физическая глина, Кстр - коэффициент структурности, КАфи критерий водопрочности 
ВЕСТНИК БУРЯТСКОГО ГОСУДАРСТВЕННОГО УНИВЕРСИТЕТА. БИОЛОГИЯ, ГЕОГРАФИЯ

Наиболее ценными агрегатами в почвах являются агрегаты размером от 10 до 0,25 мм. Механически прочные, водоустойчивые и пористые агрегаты, представленные зернистыми и мелкокомковатыми отдельностями, характеризуют агрономически ценную структуру почв. Рассчитанный по данным сухого просеивания коэффициент структурности больше 1,5 и содержание агрономически ценных агрегатов больше $60 \%$ определяют хорошую и даже отличную структурность всех почв.

КАФи для мерзлотного чернозема элювиальной позиции и чернозёма типичного определяет хорошую водопрочность агрегатов. Выщелоченный чернозем и мерзлотный чернозем транзитной позиции обладают удовлетворительной водопрочностью агрегатов.

Однако по содержанию агрегатов больше 0,25 мм водопрочность агрегатов характеризуется как неудовлетворительная для мерзлотных черноземов. Напротив, в черноземе типичном по всем показателям водопрочность агрегатов отличная, а чернозем выщелоченный обладает избыточно высокой водопрочностью агрегатов, что подтверждает характеристику данных почв. Здесь видно основное отличие черноземов европейской части страны (ЕЧС) от почв Забайкалья. И. В. Кузнецовой отмечено, что макроагрегаты $1-0,25$ и микроагрегаты в черноземных почвах являются наиболее устойчивой частью структурного состава изза высокой стабильности органического вещества (инертного гумуса), прочно связанного с минеральной частью почвы [11].

Таким образом, мерзлотные почвы, независимо от положения их в рельефе, характеризуются хорошей структурностью по результатам сухого просеивания и низкой водопрочностью. Для типичного и выщелоченного черноземов показатели структурного состояния варьируют в оптимальных пределах. В литературе есть данные о том, что прочность сухих агрегатов обусловливается кристаллизационным типом связи между элементарными почвенными частицами внутри агрегатов и формирующими веществами клеящей природы [13]. Ранее Н. И. Горбунов, Л. П. Абрукова [6] при изучении реологических свойств слитых черноземов установили преобладание в них коагуляционной структуры. При увлажнении такой почвы и ее деформировании прочность такой структуры снижается и увеличивается способность к разжижению, а при высыхании она переходит в конденсационно-кристаллизационную структуру с большой прочностью. При низкой водоустойчивости агрегатов мерзлотные почвы предрасположены к размыву и смещению почвенной массы по склону.

Многочисленными исследованиями подтверждено, что формирование водопрочной структуры происходит при взаимодействии многих почвенных процессов и при определенных как внешних, так и внутрипочвенных условиях.

При очевидной и всеми признанной определяющей роли органического вещества в формировании характерной агрегатной структуры черноземов последние исследования структурного состояния почв выявляют, что только лабильное органическое вещество способствует структурообразованию. Кроме этого, нельзя забывать и о роли почвенных коллоидов, анаэробных процессов внутри агрегатов, гидрофобности агрегатной поверхности, снижении «разрывного» действия защемленного воздуха [16]. Имеются данные, свидетельствующие об участии в образовании водопрочных агрегатов аэробно-анаэробных ассоциаций микроорганизмов [3]. В частности, Agrobacterium radiobacter образуют обильную внекле- 
Н. Н. Дармаева, Н. Б. Бадмаев, А. Ц. Мангатаев. Особенности агрегатного состава и водопрочности черноземов юга Витимского плоскогорья

точную полисахаридную слизь, которая может повышать водопрочность агрегатов [14]. Также предложена схема формирования макроагрегатов из микроагрегатов и ЭПЧ вследствие самоорганизации последних. Согласно этим данным, некоторые микроагрегаты служат связующими агентами при формировании макроагрегатов, помимо гифов грибов и корней растений [17]. Возможно, как разтаки столь явное отличие результатов сухого и мокрого просеивания объясняется способностью ЭПЧ к самоорганизации при изменении условий увлажнения и других параметров.

\section{Заключение}

Мерзлотные почвы южного склона увала Еравнинской котловины характеризуются суглинистым гранулометрическим составом. Частицы физической глины активно перемещаются по склону и аккумулируются в подножии в аллювиальной луговой почве.

При сухом просеивании в черноземах мерзлотных, независимо от местоположения на склоне, содержание агрономически ценных агрегатов высокое и наблюдается хорошая оструктуренность. Водоустойчивость агрегатов недостаточно удовлетворительная, что является показателем слабой устойчивости мерзлотных почв, формирующихся в склоновом рельефе, к эрозии.

Черноземы Руссой равнины и Южного Урала характеризуются отличным агрегатным состоянием по всем показателям. Важной положительной особенностью черноземов выщелоченных является их способность сохранять удовлетворительную макроструктуру, когда агрегаты почвы не разрушаются при воздействии воды.

Основное различие мерзлотных черноземов Еравнинской котловины от черноземов ЕЧС заключается в отсутствии водопрочной структуры, поэтому изучение мезо- и микроморфологии почв юга Витимского плоскогорья должно быть продолжено в целях уточнения их классификационного положения.

\section{Литература}

1. Бадмаев Н. Б., Куликов А. И., Корсунов В. М. Разнообразие почв криолитозоны Забайкалья. Улан-Удэ: Изд-во БНЦ СО РАН, 2006. 165 с. - Текст: непосредственный.

2. Бухонов А. В., Худяков О. И., Борисов А. В. Изменения структурного агрегатного состояния почв Нижнего Поволжья за последние 3500 лет в связи с динамикой климата // Почвоведение. 2018. № 6. С. 710-719. - Текст: непосредственный.

3. Распределение микроорганизмов и гумусовых веществ по гранулометрическим и агрегатным фракциям чернозема / Н. В. Верховцева, Е. Ю. Милановский, Е. В. Шеин, 3. Н. Тюгай // Почвы - национальное достояние России: материалы IV съезда Докучаевского общества почвоведов: в 2 книгах. Новосибирск: Наука-Центр, 2004. Т. 1. С. 3033. - Текст: непосредственный.

4. Вишнякова О. В., Чимитдоржиева Г. Д. Гуминовые кислоты лугово-черноземных мерзлотных почв Забайкалья // Почвоведение. 2008. № 17. С. 805-809. - Текст: непосредственный.

5. Воронин А. Д. Основы физики почв. Москва: Изд-во МГУ, 1986. 243 с. - Текст: непосредственный.

6. Горбунов Н. И., Абрукова А. П. Реологические свойства и минералогический состав слитых почв // Почвоведение. 1974. № 8. С. 75-85. - Текст: непосредственный. 


\section{ВЕСТНИК БУРЯТСКОГО ГОСУДАРСТВЕННОГО УНИВЕРСИТЕТА.}

7. Дармаева Н. Н., Бадмаев Н. Б. Агрофизические и реологические свойства мерзлотных почв. Улан-Удэ: Изд-во БГСХА им. В. Р. Филиппова, 2014. 123 с. - Текст: непосредственный.

8. Качинский Н. А. Структура почвы. Москва: Изд-во Моск. ун-та, 1963. 101 с. — Текст: непосредственный.

9. Когут Б. М., Сысуев С. А., Холодов В. А. Водопрочность и лабильные гумусовые вещества типичного чернозема при разном землепользовании // Почвоведение. 2012. № 5. С. 555-561. - Текст: непосредственный.

10. Королев В. А. Оценка изменения структурного состояния черноземов типичных при орошении // Вестник ВГУ. Серия: Химия. Биология. Фармация. 2006. № 1. С. 120128. - Текст: непосредственный.

11. Кузнецова И. В Содержание и состав органического вещества черноземов и его роль в образовании водопрочной структуры // Почвоведение. 1998. № 1. С. 41-50. Текст: непосредственный.

12. Куликов А. И., Дугаров В. И., Корсунов В. М. Мерзлотные почвы: экология, теплоэнергетика и прогноз продуктивности. Улан-Удэ: Изд-во БНЦ СО РАН, 1997. 312 с.

13. Моисеев К. Г., Романов И. А. Влияние длительной распашки на прочность почвенных агрегатов // Почвоведение. 2004. № 6. С. 697-701. - Текст: непосредственный.

14. Сравнительный анализ структуры микробного сообщества и количества водопрочных агрегатов чернозема выщелоченного / А. А. Романычева, О. М. Селиверстова, Н. В. Верховцева, Е. Ю. Милановский // Проблемы агрохимии и экологии. 2013. № 3. С. 30-34. - Текст: непосредственный.

15. Сенькова Л. А., Гринец Л. В. Физические и водные свойства чернозема выщелоченного южного Урала в связи с орошением // Научное обозрение. Биологические науки. 2017. № 2. С. 136-141. — Текст: непосредственный.

16. Умер М. И., Ванькова А. А. Микробиологическая активность на поверхности почвенных агрегатов // Известия ТСХА. 2011. № 6. С. 78-83. - Текст: непосредственный.

17. Холодов В. А. Способность почвенных частиц самопроизвольно образовывать макроагрегаты после цикла увлажнения и высушивания // Почвоведение. 2013. № 6. С. 698-706. - Текст: непосредственный.

18. Чимитдоржиева Г. Д. Органическое вещество почв Забайкалья / отв. ред. М. Г. Меркушева. Улан-Удэ: Изд-во БНЦ СО РАН, 2016. 388 с. - Текст: непосредственный.

19. Шеин Е. В., Милановский Е. Ю. Органическое вещество и структура почвы: учение В. Р. Вильямса и современность // Известия ТСХА. 2014. Вып. 1. С. 42-51. - Текст: непосредственный.

Статья поступила в редакциию 19.02.2021; одобрена после рецензирования 11.03.2021; принята к публикации 26.04.2021. 
Н. Н. Дармаева, Н. Б. Бадмаев, А. Ц. Мангатаев. Особенности агрегатного состава и водопрочности черноземов юга Витимского плоскогорья

FEATURES OF THE AGGREGATE COMPOSITION AND WATER STABILITY OF CHERNOZEMS IN THE SOUTH OF THE VITIM PLATEAU

Nina N. Darmaeva

Cand. Sci. (Biol.), Leading Engineer,

Laboratory of Soil Geography and Ecology,

Institute of General and Experimental Biology SB RAS

6 Sakhyanovoy St., Ulan-Ude 670047, Russia

darmaeva.nina@gmail.com

Nimazhap B. Badmaev

Dr. Sci. (Biol.), Prof. of Land Cadastre and Land Use Department ${ }^{1}$,

Deputy Director for Research, Head of Geography and Soil Ecology Laboratory ${ }^{2}$

${ }^{1}$ Dorzhi Banzarov Buryat State University

${ }^{2}$ Institute of General and Experimental Biology SB RAS

24a Smolina St., Ulan-Ude 670000, Russia

nimab@mail.ru

Aleksandr Ts. Mangataev

Cand. Sci. (Biol.), Leading Engineer,

Laboratory of Soil Geography and Ecology,

Institute of General and Experimental Biology SB RAS

6 Sakhyanovoy St., Ulan-Ude 670047, Russia

aleksandr_man@mail.ru

Abstract. The article presents a comparative analysis of the structural composition of permafrost chernozems in the south of the Vitim Plateau, chernozems of the Russian Plain (Lipetsk Oblast) and the Southern Urals (Chelyabinsk Oblast). We have revealed the differences in the structure of these soils: despite the good conditioning during dry sieving, the structure of permafrost chernozems is not water stable. Therefore, the study of meso- and micromorphology of soils in the south of the Vitim Plateau should be continued to clarify their position in the classification.

Keywords: water stability of aggregates, classification of soils, wet sieving, slope relief, structural and aggregate composition, dry sieving, clayey-illuvial permafrost chernozem, typical chernozem, leached chernozem

Acknowledgments

The work was carried out with the financial support of the RFBR grant No. 19-29-05250 mk and the research project No. 121030100228-4.

For citation

Darmaeva N. N., Gyninova A. B., Mangataev A. Ts. Features of the Aggregate Composition and Water Stability of Chernozems in the South of the Vitim Plateau. Bulletin of Buryat State University. Biology. Geography. 2021; 2: 31-39 (In Russ.).

The article was submitted 19.02.2021; approved after reviewing 11.03.2021; accepted for publication 26.04.2021. 